\title{
Predicting the distribution of Phortica variegata and potential for Thelazia callipaeda transmission in Europe and the United Kingdom
}

\author{
Jennifer Palfreyman ${ }^{1}$, John Graham-Brown ${ }^{2 *}$ (D), Cyril Caminade ${ }^{3,4}$, Paul Gilmore $^{5}$, Domenico Otranto ${ }^{6}$
} and Diana J. L. Williams ${ }^{2,5}$

\begin{abstract}
Background: Male fruitflies Phortica variegata (Drosophilidae, Steganinae) are the intermediate host of the zoonotic nematode Thelazia callipaeda (Spirurida, Thelaziidae). More than 10 years ago, when T. callipaeda was confined to remote regions of southern Italy, ecological niche models were used to predict the potential distribution of $P$. variegata across Europe and the likely risk of the nematode spreading through infected dogs travelling to/from endemic regions. As predicted, over the last 10 years T. callipaeda has spread rapidly across Europe. Recently, we identified the potential for its introduction to the UK through infected dogs travelling to/from endemic regions of mainland Europe.

Methods: Here updated information is used to re-evaluate the model-predicted European, and specifically, UK distribution to determine the likelihood of T. callipaeda becoming established. Additionally, the UK distribution of $P$. variegata was further investigated through snapshot fly trapping at model-predicted locations.

Results: Ecological niche modelling using Genetic Algorithm for Rule-set Prediction (GARP) analysis suggests a European range similar to that described previously, with some indication of potential spread further eastward. Finer scale UK mapping suggested that $P$. variegata presence was limited mostly to southern England, but highlighted regions where $P$. variegata has not been documented previously. The arbitrary fly trapping identified activity of $P$. variegata at two locations where the species has been found previously late in the season. No specimens were collected at model-predicted locations, although habitat suitable for the species was identified.

Conclusions: GARP-model prediction of $P$. variegata distribution suggests presence of suitable conditions in previously undocumented regions of the UK and Europe and highlight the possibility for further spread of T. callipaeda across Europe, including the UK. Further work to validate the P. variegata UK model with field data will help improve its accuracy in predicting suitable areas, whilst surveillance of sylvatic definitive host species in such locations is advised to monitor for evidence of autochthonous T. callipaeda transmission.
\end{abstract}

Keywords: Phortica variegata, Thelazia callipaeda, Dipteran vectors, Zoonosis, Ecological niche modelling

\footnotetext{
* Correspondence: xp0u405d@liv.ac.uk

${ }^{2}$ Infection Biology, Institute of Infection and Global Health, University of

Liverpool, Liverpool, UK

Full list of author information is available at the end of the article
}

(c) The Author(s). 2018 Open Access This article is distributed under the terms of the Creative Commons Attribution 4.0 International License (http://creativecommons.org/licenses/by/4.0/), which permits unrestricted use, distribution, and reproduction in any medium, provided you give appropriate credit to the original author(s) and the source, provide a link to the Creative Commons license, and indicate if changes were made. The Creative Commons Public Domain Dedication waiver (http://creativecommons.org/publicdomain/zero/1.0/) applies to the data made available in this article, unless otherwise stated. 


\section{Background}

Thelazia callipaeda (Spirurida: Thelaziidae) is a vector borne, zoonotic nematode of animal and public health importance capable of infecting a range of host species, including dogs and cats, foxes, wolves, rabbits and humans [1]. Adult worms reside in the conjunctiva and surrounding structures of their definitive host, causing a range of clinical outcomes from asymptomatic carriage through to severe ocular pathology including blepharitis, conjunctivitis and corneal ulceration [2]. In recent years, T. callipaeda appears to have spread rapidly through Europe: since 2003 the list of endemic countries has expanded from Italy [3], where autochthonous transmission was first recorded in Europe, to include France, Switzerland, Germany, Spain, Portugal, Bosnia and Herzegovina, Croatia, Romania, Bulgaria, Hungary, Greece, Slovakia and Serbia [4-15]. Zoonotic infections have been diagnosed in endemic regions of Europe on several occasions, demonstrating the importance of its spread to public health [2, 15-17]. To date, DNA sequence analysis of the mitochondrial cytochrome $c$ oxidase subunit 1 ( $\operatorname{cox} 1)$ gene performed on specimens collected from several different host species across Europe has demonstrated presence of a single haplotype (h1). This suggests spread of T. callipaeda in Europe has occurred from a single introduction event and/or that this haplotype (h1) is well adapted for survival and transmission in Europe [18].

Travel of companion animals between European countries provides an opportunity for further dissemination of $T$. callipaeda. For example, in 2016 patent infections were imported to the UK on at least two occasions in animals with a history of travel to $T$. callipaeda endemic areas [19], whilst the introduction of the parasite to Spain is thought to have occurred through the importation of infected hunting dogs from Italy and France [8]. Furthermore, zoonotic infections acquired during travel abroad may also facilitate the introduction of T. callipaeda to non-endemic countries on a global scale, emphasising the need for a "One Health" approach for the surveillance of such disease [20].

A critical determinant of $T$. callipaeda spread and distribution is the presence of intermediate host species. In Europe, males of Phortica variegata (Drosophilidae: Steganinae) are intermediate hosts and vectors under natural conditions [21]. These flies are typically associated with oak (Quercus spp.) woodland habitats and fruit farms [21] and primarily feed on fermenting sap runs and fruit. Additionally (and importantly), males exhibit zoophagic behaviour, feeding on the lacrimal secretions of humans and animals [21]. It is through this behaviour that male flies transmit $T$. callipaeda, becoming infected through the ingestion of L1 larvae when feeding on infected hosts, and depositing infective L3 larvae onto the eyes of new definitive hosts when they feed again. Development from L1 to L3 occurs on the surface of testes of the fly, at which point infective L3 larvae migrate to the oesophagus and proboscis to be transmitted to a definitive host [22]. This process typically takes 14-21 days from the point of ingestion. In southern Europe, flies are active from May to October with optimal temperatures $\left(20-25^{\circ} \mathrm{C}\right.$ ) and humidity (50-70\%) present in July and August leading to greater activity and likelihood for T. callipaeda transmission at this time [21, 23]. Ecological niche modelling in 2006 demonstrated that the potential distribution of $P$. variegata ranged widely across southern and central Europe, extending as far north as Denmark, the southern tip of Sweden and south-eastern England [23].

Whilst $P$. variegata is present in the UK, it is currently listed as a species of conservation concern under Section 41 of the Natural Environment and Rural Communities Act 2006 [24]. There have, however, been a number of observations of this species in recent years [25]. Additionally, questions exist concerning its biology and ecology in the UK including the length of its active flying season. Understanding both geographical distribution and the length of flying season of $P$. variegata are of importance when evaluating the potential for $T$. callipaeda introduction to the UK and the likelihood of autochthonous transmission occurring, especially in wild carnivores such as foxes.

The aim of this study was to re-visit the Genetic Algorithm for Rule-set Prediction (GARP) model analysis described by Otranto et al. [23] to predict ecological niche distribution for $P$. variegata across Europe using updated climate data and $P$. variegata records. This is important given recent climate change trends in Europe and the UK. Furthermore, to help determine whether autochthonous transmission of $T$. callipaeda might occur, particular consideration was given to the UK through fine-scale mapping and field sampling for model validation.

\section{Methods}

\section{Ecological niche modelling}

GPS co-ordinates were obtained from European records $[26,27]$, and derived from the UK literature [25, 28-30]. To avoid retrospective extrapolation of climate data, only locations recorded post 1950 were selected for inclusion. Only a single observation per GPS coordinate was included to avoid duplication of data. These selection criteria yielded 243 locations for $P$. variegata from across Europe (at longitudes from $8^{\circ} \mathrm{W}-48^{\circ} \mathrm{E}$ and latitudes from $36^{\circ} \mathrm{N}-63^{\circ} \mathrm{N}$ ) including 19 from the UK. Seventy-one locations were newly identified since 2006. 
The software application DesktopGarp (http://nhm.ku. edu/desktopgarp) was used to model $P$. variegata distribution across Europe and, specifically, the UK. For European models, spatial datasets for fixed variables included mapped altitude $(\mathrm{m})$ and slope from the ETOPO1 dataset [31], meteorological records (19592015) for annual mean rainfall $(\mathrm{mm})$, temperature $\left({ }^{\circ} \mathrm{C}\right)$, diurnal temperature range or DTR $\left({ }^{\circ} \mathrm{C}\right)$, wet days (defined as days above $1 \mathrm{~mm}$ rainfall), potential evapotranspiration or PET $(\mathrm{mm})$ [32], and solar irradiance $\left(\mathrm{W} / \mathrm{m}^{2}\right)$ derived from satellite estimates [33]. All fields were interpolated to a regular $0.25^{\circ} \times 0.25^{\circ}$ spatial grid (at longitudes from $23.875^{\circ} \mathrm{W}-45.375^{\circ} \mathrm{E}$ and latitudes from $\left.30^{\circ} \mathrm{N}-71.375^{\circ} \mathrm{N}\right)$.

For UK models a higher spatial resolution was obtained through interpolation to a regular $0.05^{\circ} \times 0.05^{\circ}$ spatial grid (at longitudes from $12^{\circ} \mathrm{W}-4^{\circ} \mathrm{E}$ and latitudes from $49^{\circ} \mathrm{N}-60^{\circ} \mathrm{N}$ ). Altitude data was again derived from the ETOPO1 dataset, whilst meteorological records (1977-2015) for temperature, DTR, wet days, sunshine duration (hours per day) and PET data were based on the UKCP09 gridded observation dataset [34] available at $5 \times 5 \mathrm{~km}$.

The model for Europe was calculated using all 243 points of $P$. variegata presence dating from 1959-2015. For the UK, 19 points were available dating from 19772015. As part of the GARP modelling process, pseudoabsence data points equal to the number of presence points were also randomly generated and incorporated into the analyses. The reader is invited to refer to Stockwell and Peter, 1999 for further details about this algorithm [35]. Statistical parameters set for both models were 100 runs, 0.01 coverage and 1000 of maximum iterations with rules set as negated range and logistic regression only. Models with a non-zero omission error and significance values of lower than 0.05 (95\% confidence interval) were retained. This resulted in $16 / 100$ and 33/100 models being used for Europe and the UK, respectively. Heat maps were constructed showing the percentage of models agreeing on suitable areas for $P$. variegata for each interpolated spatial grid point (see Fig. 1), instead of using a median estimate based on the multi-model ensemble [23].

\section{Field sampling}

To evaluate model accuracy, and to try and identify and generate additional $P$. variegata occurrence data, six locations were visited in late summer 2017. Firstly, to establish an effective sampling protocol three locations where $P$. variegata has previously been identified were visited in the last week of August (Table 1). Following successful identification of $P$. variegata at two of these locations, a further three locations were sampled the following week (Table 1). These locations were areas of dense deciduous woodland (including Quercus spp.) located at (or close to) areas where the newly developed UK GARP model predicted the potential presence of $P$. variegata. This was achieved by overlaying the fine scale $\left(0.05^{\circ} \times 0.05^{\circ}\right.$ spatial grid) UK map in Google Earth Pro (https://www.google.com/earth/) [36].

Locations with areas of established oak woodland with scrub undergrowth were chosen for trapping due to their suitability as habitat for $P$. variegata. Sampling at each location consisted a four hour period between 10: 00 and 14:00 $\mathrm{h}$ on the date specified (Table 1). Bait consisted of fermented fruit (chopped banana, apple and pear sealed in an airtight container and left at room temperature for $48 \mathrm{~h}$ ) used with either a sweep net to catch visiting flies, or in four bottle traps prepared as previously described $[21,37]$ and hung in the vicinity for the duration of the sampling period. Both bait and bottle traps were hung at a height of $1-2 \mathrm{~m}$ above ground level.

All the specimens collected were preserved in 70\% ethanol on the day of trapping to retain both morphological and molecular integrity for species identification, dissection and (if indicated) PCR analysis. Phortica variegata were positively identified through comparison to previously described morphological features [23]. Male $P$. variegata specimens were dissected to check for $T$. callipaeda infection status: the thorax (oesophagus), head and proboscis were dissected and examined under low power magnification $(\times 4-10)$ for infective third stage larvae, whilst testicular tissue was removed and examined under higher magnification $(\times 20-40)$ for encysted first and second stage larvae. Had nematodes been observed, the intention was to establish their identity through a combination of morphological description and molecular analysis.

\section{Results}

The European distribution predicted by the GARP model (Fig. 1a) indicated that large areas are suitable for the development of $P$. variegata, with the geographic range extended further east (e.g. over Ukraine, Russia and northern Turkey) compared to that published by Otranto et al. [23]. Finer scale mapping of $P$. variegata distribution in the UK (Fig. 1b) showed it was likely to be limited to the south and east of England. This included locations where $P$. variegata has been identified previously (south Gloucestershire, Dorset, Hampshire and Kent), and also regions where no prior records exist including Surrey, Sussex, Suffolk, Essex, Somerset and Worcestershire (Fig. 1b). This map has been made publicly accessible through the University of Liverpool's online research data catalogue (http://datacat.liverpool.ac.uk/id/ eprint/434) [36].

Field sampling at locations where $P$. variegata had previously been identified yielded four specimens in two 


\section{$\mathbf{a}$}

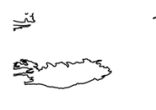

b

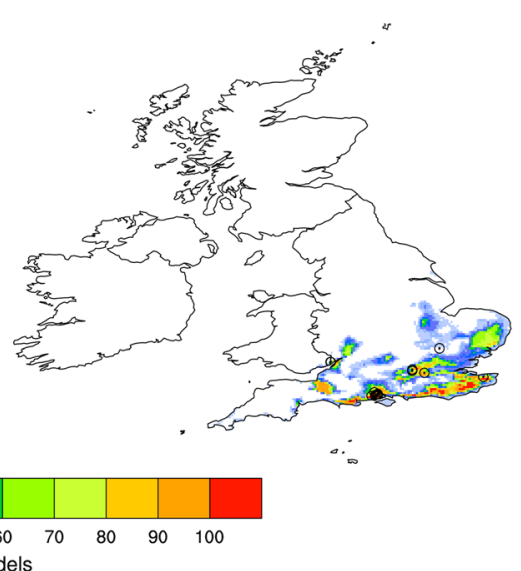

Fig. 1 Predicted geographical distribution of Phortica variegata across (a) Europe $\left(0.25^{\circ} \times 0.25^{\circ}\right.$ spatial grid, $23.875^{\circ} \mathrm{W}-45.375^{\circ} \mathrm{E}$ and $\left.30^{\circ} \mathrm{N}-71.375^{\circ} \mathrm{N}\right)$ and (b) the UK $\left(0.05^{\circ} \times 0.05^{\circ}\right.$ spatial grid, $12^{\circ} \mathrm{W}-4^{\circ} \mathrm{E}$ and $\left.49^{\circ} \mathrm{N}-60^{\circ} \mathrm{N}\right)$. Heat map coloration denotes the percentage of models $(n=16$ and $n=33$, respectively) agreeing on suitability for each grid point. Observed locations of $P$. variegata used to train the models are depicted by location points

of the three localities (Table 1). All P. variegata specimens were collected through sweep net trapping around fermented fruit bait, none were caught in the bottle traps. Specimens were identified morphologically as $P$. variegata based on key features (Fig. 2): briefly, specimens measured
$3.5-5 \mathrm{~mm}$ in length, with red coloured eyes encircled by a pale white ring (Fig. 2b); the arista of each antenna had three to six short dorsal branches of decreasing length towards the tip (Fig. 2c); the scutum was patterned with dark, confluent spots; the discal and second basal wing

Table 1 Baiting locations and observations from field sampling

\begin{tabular}{|c|c|c|c|c|c|}
\hline Bait site & Latitude & Longitude & Date & Reference & Phortica presence (Notes) \\
\hline 1. Ban-y-gor, Gloustershire & $51.6678^{\circ} \mathrm{N}$ & $2.6703^{\circ} \mathrm{W}$ & 28/08/17 & {$[30]$} & $\begin{array}{l}\text { No Phortica collected. } \\
\text { (Deciduous woodland containing Quercus } \\
\text { spp. Baited oak with small drying sap run. } \\
\text { Overcast day with cool ambient } \\
\text { temperatures). }\end{array}$ \\
\hline 2. New Forest, Hampshire & $50.8421^{\circ} \mathrm{N}$ & $1.5147^{\circ} \mathrm{W}$ & 29/08/17 & {$[25]$} & $\begin{array}{l}\text { Three Phortica (1M, 2F) collected by sweep } \\
\text { net. } \\
\text { (Oak woodland. Sunny day with warm } \\
\text { ambient temperature). }\end{array}$ \\
\hline $\begin{array}{l}\text { 3. High Standing Hill, } \\
\text { Windsor Forest }\end{array}$ & $51.4694^{\circ} \mathrm{N}$ & $0.6714^{\circ} \mathrm{W}$ & $30 / 08 / 17$ & {$[28]$} & $\begin{array}{l}\text { One Phortica (F) collected by sweep net. } \\
\text { (Deciduous woodland containing Quercus } \\
\text { spp. Initially warm sunny day with } \\
\text { conditions deteriorating to rainy and } \\
\text { overcast with cool ambient temperatures). }\end{array}$ \\
\hline $\begin{array}{l}\text { 4. Collin's Wood Nature } \\
\text { Reserve, Gloucestershire }\end{array}$ & $51.9477^{\circ} \mathrm{N}$ & $2.3682^{\circ} \mathrm{W}$ & 04/09/17 & Model-predicted ${ }^{a}$ & $\begin{array}{l}\text { No Phortica collected. } \\
\text { (Suitable habitat identified: deciduous } \\
\text { woodland containing Quercus spp. and } \\
\text { commercial apple orchard adjacent. Baited } \\
\text { oak with large fragrant sap run. Overcast } \\
\text { day with warm ambient temperatures and } \\
\text { humid conditions). }\end{array}$ \\
\hline 5. Castle Neroche, Somerset & $50.9360^{\circ} \mathrm{N}$ & $3.0342^{\circ} \mathrm{W}$ & 05/09/17 & Model-predicted ${ }^{a}$ & $\begin{array}{l}\text { No Phortica collected. } \\
\text { (Suitable habitat identified: Oak forest. } \\
\text { Wet and windy conditions with cool } \\
\text { ambient temperatures). }\end{array}$ \\
\hline $\begin{array}{l}\text { 6. Rendlesham Forest, } \\
\text { Suffolk }\end{array}$ & $52.0799^{\circ} \mathrm{N}$ & $1.4329^{\circ} \mathrm{E}$ & 06/09/17 & Model-predicted ${ }^{a}$ & $\begin{array}{l}\text { No Phortica collected. } \\
\text { (Suitable habitat identified: Oak forest. } \\
\text { Sunny day with warm ambient } \\
\text { temperatures). }\end{array}$ \\
\hline
\end{tabular}

${ }^{a}$ Model-predicted locations were identified by overlaying GARP model-generated fine-scale map of UK $P$. variegata distribution (Fig. 1b) on satellite images to locate areas of suitable habitat (woodland) in regions with high model-predicted likelihood of $P$. variegata presence 


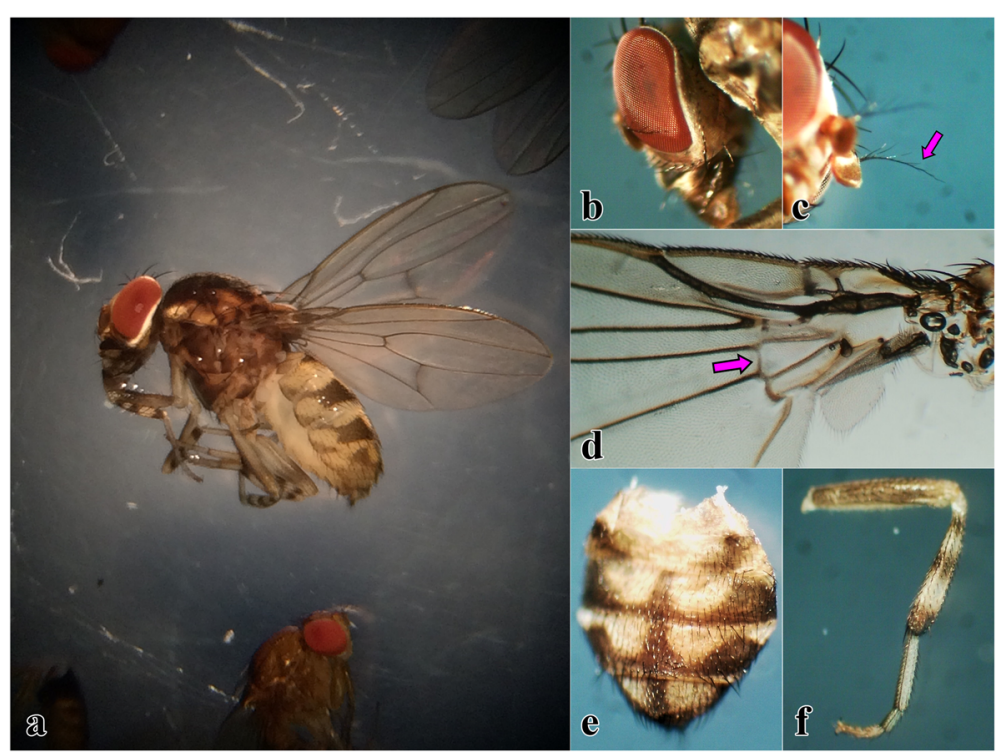

Fig. 2 Morphological features of Phortica variegata including (a) an intact female; (b) red coloured eyes encircled by a pale white ring; (c) the arista of the antenna with four short dorsal branches (arrow) decreasing in length towards the apical tip; (d) an additional cross-vein separating the discal and second basal wing cells (arrow) plus two interruptions of the costal vein- a characteristic feature of Drosophilidae; (e) the abdomen with three transversal and one longitudinal dark band on a paler sub-colour; and ( $\mathbf{f}$ legs with three dark bands around the tibia and dark coloured coxae and femur

cells were separated by an additional cross-vein (Fig. 2d); the abdomen had a yellow and brown pattern consisting of three transversal and one longitudinal dark band on a paler sub-colour (Fig. 2e); the legs had three distinctive dark bands around the tibia, dark coloured coxae and femur, with the latter also having a paler base and apex (Fig. 2f) [23].

No $P$. variegata were collected from the three locations predicted to be suitable by the model, although at all three suitable habitat was found in the form of oak (Quercus spp.) woodland with underlying scrubland (Table 1). Furthermore, evidence of active sap runs were detected on some trees and at one location a commercial apple orchard was also found in the immediate vicinity (Table 1). All six locations had public footpaths. Owners were regularly observed walking their dogs through these areas. A single male $P$. variegata was caught at one location where $P$. variegata had been documented previously (Table 1), but no nematode larvae were detected following dissection.

\section{Discussion}

Our study updates the ecological niche model by Otranto et al. [23], which was based on 240 known locations of $P$. variegata from across Europe and used climatic data from 1960-1990. Subsequent reports of autochthonous transmission in multiple European countries in the intervening period have proven the validity of that approach, namely determining the ecological and environmental conditions suitable for P. variegata [5-9, 11-15]. In the current study, ecological niche model analysis using up to date climate information and 71 new $P$. variegata locations indicates the potential for further introduction of T. callipaeda to new regions of Europe, including the UK.

The ecological niche models presented here for Europe are largely in agreement with those described previously [23], but suggest an increase in the distribution range of $P$. variegata eastward to include new regions of the Ukraine, Turkey and Russia. To date, autochthonous transmission of T. callipaeda in Europe has been limited to a single haplotype (h1), in contrast there are at least twenty additional haplotypes present in southeast Asia [18, 38, 39]. Recent phylogenetic analysis of T. callipaeda isolates identified a divergence between European $\mathrm{h} 1$ and those haplotypes present in Asian countries during the Pleistocene epoch, suggesting two separate sub-populations [39]. The presence of just a single haplotype in Europe may be the result of either a specific genetic adaption of T. callipaeda h1 which enables its survival and propagation in Europe, or an indication that its spread in Europe was the result of a single introduction of T. callipaeda h1 to the continent. If the latter is true, expansion of $P$. variegata range eastward increases the likelihood of further introductions of T. callipaeda from Asia, including new haplotypes with unknown consequences for the biology and epidemiology of $T$. callipaeda in Europe, specifically its prevalence, incidence and zoonotic potential. 
GARP model analysis suggests the most suitable areas for $P$. variegata in the UK are in southeast England. In many instances these regions intersect with national parks such as the New Forest, Windsor Forest, Wye Valley, South Downs and parts of the Kent Downs; many of these locations are popular areas for dog walking. This scenario could bring competent definitive and intermediate hosts of $T$. callipaeda into close proximity. If dogs infected with T. callipaeda as a result of travel to endemic European regions are exercised in such areas, autochthonous transmission to $P$. variegata in the UK is a possibility. Furthermore, such national parks are home to numerous sylvatic species (e.g. red foxes, hares and rabbits) which are themselves competent definitive wild hosts for $T$. callipaeda [1, 40]. This readily available wildlife reservoir further increases the possibility of $T$. callipaeda becoming established in the UK.

The single male $P$. variegata specimen collected was not infected with $T$. callipaeda. However, given that the infection rate in $P$. variegata is $\sim 1 \%$ under natural conditions [21] the probability of detecting autochthonous transmission by this method is very low. For surveillance purposes, a more realistic approach would be to passively monitor $T$. callipaeda infection in sylvatic species in regions where $P$. variegata presence is already known.

Overlaying the UK map as a layer in Google Earth $\mathrm{Pro}^{\circ}$ allowed the identification of potential $P$. variegata sites by locating areas of woodland within these hotspot areas [36]. This approach demonstrates a major advantage of ecological niche modelling, since it facilitates a more targeted approach to both field sampling for $P$. variegata and surveillance for autochthonous $T$. callipaeda transmission. Whilst we were unable to confirm $P$. variegata presence in locations predicted by the new GARP model, we were able to identify habitat suitable for the species, specifically extensive Quercus spp. woodland. The inclement weather conditions (Table 1) and relative lateness in the season for sampling may have hindered our detection of $P$. variegata even if they were present. Further field sampling at such sites in summer months would help establish the presence or absence of P. variegata more definitively. Additional observations could then be incorporated into updated versions of the UK GARP model for $P$. variegata distribution to improve its accuracy, or derive risk maps on a per month basis.

The vector competence of $P$. variegata from geographical areas where T. callipaeda is not yet present, such as the USA, has been recently demonstrated under laboratory conditions [41], confirming the potential for autochthonous transmission in areas where the parasite is not endemic but the vector occurs, such as the UK. We have confirmed that, under favourable climatic conditions, adult $P$. variegata were still active in the UK in the last week of August. Falk [25] noted previously that $P$. variegata activity in the UK was observed in June and July, but that the full extent of their active flying season was unknown. Current evidence would suggest an active flying season in the south of the UK from May through to September [25, 30]. Importantly, with respect to its role as a vector of $T$. callipaeda, this would enable transmission in the UK to occur within a single flying season, since the minimum time required for development of first-stage larvae to infective third-stage larvae is $14-21$ days [22].

The ability of infected $P$. variegata to successfully overwinter has been demonstrated experimentally [22]. Additionally, T. callipaeda L3 and L4 larvae recovered from $P$. variegata and dogs, respectively, at the beginning of the active flying season suggesting delayed transmission to the following flying year is possible under natural conditions [21]. In cooler northern latitudes the ability of infected $P$. variegata to overwinter may prove to be an important additional feature in determining whether such fly populations are capable of sustaining autochthonous transmission of T. callipaeda.

\section{Conclusions}

By updating and developing ecological niche models of P. variegata distribution across Europe and the UK, respectively, we have confirmed its predicted range and indicate the potential for expansion to new regions. In the UK, this has implications with respect to the potential for autochthonous transmission of T. callipaeda following its introduction from mainland Europe. Passive surveillance of sylvatic species is suggested to monitor for autochthonous $T$. callipaeda transmission. In addition, research to determine and improve the accuracy of GARP models and/or introduce temporal components to consider seasonal and annual range variation would further help monitor the distribution of $P$. variegata and the subsequent risk of T. callipaeda infection to both human and animal populations.

\section{Abbreviations \\ GARP: Genetic Algorithm for Rule-set Prediction; JNCC: Joint Nature Conservation Committee; NIHR: National Institute for Health Research; UK: United Kingdom (of Great Britain and Northern Ireland); USA: United States of America}

\section{Acknowledgements}

We would like to thank Mr Steven Falk for his helpful advice and expertise in UK P. variegata locations, Professor Matthew Baylis and Mr Kenneth Sherlock for their advice and the kind provision of trapping equipment for field work and Dr John McGarry for the kind provision of dichotomous identification keys. We would like to thank the Mett Office for providing EOBS data and the NIHR. We acknowledge the E-OBS dataset from the EU-FP6 project ENSEMBLES (http://ensembles-eu.metoffice.com) and the data providers in the ECA\&D project (http://www.ecad.eu). @ Crown Copyright 2009. The UK Climate Projections (UKCP09) have been made available by the Department for Environment, Food and Rural Affairs (Defra) and the Department of Energy and Climate Change (DECC) under licence from the Met Office, UKCIP, British Atmospheric Data Centre, Newcastle University, University of 
East Anglia, Environment Agency, Tyndall Centre and Proudman Oceanographic Laboratory. These organisations give no warranties, express or implied, as to the accuracy of the UKCP09 and do not accept any liability for loss or damage, which may arise from reliance upon the UKCP09 and any use of the UKCP09 is undertaken entirely at the users risk. The views expressed are those of the author(s) and not necessarily those of the NHS, the NIHR, the Department of Health, and Public Health England.

\section{Funding}

This study was funded through a clinical Wellcome summer studentship awarded to JP, JGB, CC \& DW and the University of Liverpool Institute of Veterinary Science's Veterinary Research Project Support scheme awarded to JGB. CC was funded by the National Institute for Health Research Health Protection Research Unit (NIHR HPRU) in Emerging and Zoonotic Infections at the University of Liverpool in partnership with Public Health England (PHE) and the Liverpool School of Tropical Medicine (LSTM).

\section{Availability of data and materials}

All data used to generate the GARP model analyses described in this manuscript are accessible through published literature and databases as described in the Methods and Acknowledgements sections. The $0.05^{\circ} \times$ $0.05^{\circ}$ resolution UK GARP model described for $P$. variegata is publicly accessible through the University of Liverpool's online research data catalogue

(http://datacat.liverpool.ac.uk/id/eprint/434).

\section{Authors' contributions}

Study conception and design was carried out by JGB, DW, PG, CC and JP. Manuscript preparation was carried out by JP, CC, JGB, DO and DW. Model design, GPS data gathering and mapping was performed by CC and JP based on the original "GARP" model analysis of DO. Field sampling was performed by JP and JGB. Laboratory work was performed by JP, PG and JGB.

All authors read and approved the final version of the manuscript.

\section{Competing interests}

The authors declare that they have no competing interests.

\section{Publisher's Note}

Springer Nature remains neutral with regard to jurisdictional claims in published maps and institutional affiliations.

\section{Author details}

'Institute of Veterinary Science, University of Liverpool, Liverpool, UK. ${ }^{2}$ Infection Biology, Institute of Infection and Global Health, University of Liverpool, Liverpool, UK. ${ }^{3}$ Epidemiology and Population Health, Institute of Infection and Global Health, University of Liverpool, Liverpool, UK. ${ }^{4} \mathrm{NIHR}$, Health Protection Research Unit in Emerging and Zoonotic Infections, Liverpool, UK. ${ }^{5}$ Liverpool Veterinary Parasitology Diagnostics, University of Liverpool, Liverpool, UK. ${ }^{6}$ Dipartimento di Medicina Veterinaria, University of Bari, Bari, Italy.

\section{Received: 12 January 2018 Accepted: 9 April 2018}

Published online: 27 April 2018

\section{References}

1. Otranto D, Dantas-Torres F, Mallia E, DiGeronimo PM, Brianti E, Testini G, et al. Thelazia callipaeda (Spirurida, Thelaziidae) in wild animals: report of new host species and ecological implications. Vet Parasitol. 2009;166:262-7.

2. Otranto D, Dutto M. Human thelaziasis, Europe. Emerg Infect Dis. 2008;14:647-9.

3. Otranto D, Ferroglio E, Lia RP, Traversa D, Rossi L. Current status and epidemiological observation of Thelazia callipaeda (Spirurida, Thelaziidae) in dogs, cats and foxes in Italy: a "coincidence" or a parasitic disease of the Old Continent? Vet Parasitol. 2003;116:315-25.

4. Rossi L, Bertaglia PP. Presence of Thelazia callipaeda Railliet \& Henry, 1910, in Piedmont, Italy. Parassitologia. 1989;31:167-72.

5. Dorchies P, Chaudieu G, Simeon LA, Cazalot G, Cantacessi C, Otranto D. First reports of autochthonous eyeworm infection by Thelazia callipaeda (Spirurida, Thelaziidae) in dogs and cat from France. Vet Parasitol. 2007;149: 294-7.
6. Malacrida F, Hegglin D, Bacciarini L, Otranto D, Nageli F, Nageli C, et al. Emergence of canine ocular thelaziosis caused by Thelazia callipaeda in southern Switzerland. Vet Parasitol. 2008;157:321-7.

7. Magnis J, Naucke TJ, Mathis A, Deplazes P, Schnyder M. Local transmission of the eye worm Thelazia callipaeda in southern Germany. Parasitol Res. 2010;106:715-7.

8. Miro G, Montoya A, Hernandez L, Dado D, Vazquez MV, Benito M, et al. Thelazia callipaeda: infection in dogs: a new parasite for Spain. Parasit Vectors. 2011:4:148.

9. Vieira L, Rodrigues FT, Costa A, Diz-Lopes D, Machado J, Coutinho T, et al. First report of canine ocular thelaziosis by Thelazia callipaeda in Portugal. Parasit Vectors. 2012;5:124.

10. Hodzic A, Latrofa MS, Annoscia G, Alic A, Beck R, Lia RP, et al. The spread of zoonotic Thelazia callipaeda in the Balkan area. Parasit Vectors. 2014;7:352.

11. Mihalca AD, D'Amico G, Scurtu I, Chirila R, Matei IA, Ionica AM. Further spreading of canine oriental eyeworm in Europe: first report of Thelazia callipaeda in Romania. Parasit Vectors. 2015:8:48.

12. Papadopoulos E, Komnenou A, Thomas A, loannidou E, Colella V, Otranto D. Spreading of Thelazia callipaeda in Greece. Transbound Emerg Dis. 2017;65: 248-252.

13. Cabanova V, Kocak P, Vichova B, Miterpakova M. First autochthonous cases of canine thelaziosis in Slovakia: a new affected area in central Europe. Parasit Vectors. 2017;10:179.

14. Colella V, Kirkova Z, Fok E, Mihalca AD, Tasic-Otasevic S, Hodzic A, et al. Increase in eyeworm infections in eastern Europe. Emerg Inf Dis. 2016;22: 1513-5.

15. Tasic-Otasevic S, Gabrielli S, Trenkic-Bozinovic M, Petrovic A, Gajic B, Colella $\checkmark$, et al. Eyeworm infections in dogs and in a human patient in Serbia: a One Health approach is needed. Comp Immunol Microbiol Infect Dis. 2016; 45:20-2.

16. Fuentes I, Montes I, Saugar JM, Latrofa S, Garate T, Otranto D. Thelaziosis in humans, a zoonotic infection, Spain, 2011. Emerg Infect Dis. 2012;18:2073-5.

17. Paradzik MT, Samardzic K, Zivicnjak T, Martinkovic F, Janjetovic Z, MileticMedved M. Thelazia callipaeda - first human case of thelaziosis in Croatia. Wien Klin Wochenschr. 2016;128:221-3.

18. Otranto D, Testini G, De Luca F, Hu M, Shamsi S, Gasser RB. Analysis of genetic variability within Thelazia callipaeda (Nematoda: Thelazioidea) from Europe and Asia by sequencing and mutation scanning of the mitochondrial cytochrome c oxidase subunit 1 gene. Mol Cell Probes. 2005; 19:306-13.

19. Graham-Brown J, Gilmore P, Colella V, Moss L, Dixon C, Andrews M, et al. Three cases of imported eyeworm infection in dogs: a new threat for the United Kingdom. Vet Rec. 2017;181:346.

20. McGarry JW, Graham-Brown J, Pasztor M. Threats of vector-borne zoonotic disease in Europe: dogs, drosophilids, and Oriental eye worm. Lancet Infect Dis. 2017;17:1115-7

21. Otranto D, Cantacessi C, Testini G, Lia RP. Phortica variegata as an intermediate host of Thelazia callipaeda under natural conditions: evidence for pathogen transmission by a male arthropod vector. Int J Parasitol. 2006: 36:1167-73

22. Otranto D, Lia RP, Cantacessi C, Testini G, Troccoli A, Shen JL, et al. Nematode biology and larval development of Thelazia callipaeda (Spirurida, Thelaziidae) in the drosophilid intermediate host in Europe and China. Parasitology. 2005;131:847-55.

23. Otranto D, Brianti E, Cantacessi C, Lia RP, Maca J. The zoophilic fruit fly Phortica variegata: morphology, ecology and biological niche. Med Vet Entomol. 2006;20:358-64.

24. JNCC. UK Priority Species data collation: Amiota variegata version 2. 2010. http://jncc.defra.gov.uk/_speciespages/2028.pdf.

25. Falk S. Surveys of Phortica variegata (Diptera: Drosophilidae) in 2014 with a compilation of other recent records. Buglife - The Invertebrate Conservation Trust; 2015.

26. Scachetti-Pereira, R. (2002), DesktopGarp: a software package for biodiversity and ecologic research. United States: The University of Kansas Biodiversity Research Center

27. Bächli G. TaxoDros v1.04. In: The database on Taxonomy of Drosophilidae 2017. https://www.taxodros.uzh.ch/.

28. Chandler P. Phortica variegata (Fallén) (Diptera, Drosophilidae) at Bushy Park Middlesex and Windsor Forest, Berkshire. Dipterists Dig. 2014;21:149-50.

29. Clemons L. Phortica variegata (Fallén, 1823) (Diptera, Drosophilidae) in Kent. Dipterists Dig. 2009;16:25. 
30. Gibbs D. Amiota variegata (Diptera, Drosophilidae) new for Gloucestershire. Dipterists Dig. 2003;10:113.

31. Amante C, Eakins BW. ETOPO1 1 Arc-Minute Global Relief Model: Procedures, Data Sources and Analysis. NOAA Technical Memorandum NESDIS NGDC-24. National Geophysical Data Center, NOAA. 2009.

32. Haylock MR, Hofstra N, Klein Tank AMG, Klok EJ, Jones PD, New M. A European daily high-resolution gridded data set of surface temperature and precipitation for 1950-2006. J Geophys Res. 2008;113:D20119.

33. Karlsson K-G, Anttila K, Trentmann J, Stengel M, Fokke Meirink J, Devasthale A, et al. CLARA-A2: the second edition of the CM SAF cloud and radiation data record from 34 years of global AVHRR data. Atmos Chem Phys. 2017; 17:5809-28.

34. Jenkins G, Perry M, Prior J. The Climate of the UK and Recent Trends. 2009. http://www.ukcip.org.uk/wp-content/PDFs/UKCP09_Trends.pdf.

35. Stockwell D, Peters D. The GARP modelling system: problems and solutions to automated spatial prediction. Int J Geogr Inf Sci. 1999;13:143-58.

36. Palfreyman J, Caminade C, Graham-Brown J, Williams DJL. Genetic Algorithm for rule-set prediction (GARP) model for Phortica variegata presence in the UK (version 2). 2018. https://doi.org/10.17638/datacat. liverpool.ac.uk/417.

37. Roggero C, Schaffner F, Bachli G, Mathis A, Schnyder M. Survey of Phortica drosophilid flies within and outside of a recently identified transmission area of the eye worm Thelazia callipaeda in Switzerland. Vet Parasitol. 2010; 171:58-67.

38. Zhang X, Shi YL, Wang ZQ, Duan JY, Jiang P, Liu RD, et al. Morphological and mitochondrial genomic characterization of eyeworms (Thelazia callipaeda) from clinical cases in central China. Front Microbiol. 2017;8:1335.

39. Zhang X, Shi YL, Han LL, Xiong C, Yi SQ, Jiang P, et al. Population structure analysis of the neglected parasite Thelazia callipaeda revealed high genetic diversity in Eastern Asia isolates. PLoS Negl Trop Dis. 2018;12:e0006165.

40. Gama A, Pires I, Canado M, Coutinho T, Lopes AP, Latrofa MS, et al. First report of Thelazia callipaeda infection in wild European rabbits (Oryctolagus cuniculus) in Portugal. Parasit Vectors. 2016;9:236.

41. Otranto D, latta R, Lia RP, Cavalera MA, Màca J, Pombi M, et al. Competence of Phortica variegata from the United States as intermediate host of Thelazia callipaeda eyeworm. Am J Trop Med Hyg. 2018. In press.

Ready to submit your research? Choose BMC and benefit from:

- fast, convenient online submission

- thorough peer review by experienced researchers in your field

- rapid publication on acceptance

- support for research data, including large and complex data types

- gold Open Access which fosters wider collaboration and increased citations

- maximum visibility for your research: over $100 \mathrm{M}$ website views per year

At BMC, research is always in progress.

Learn more biomedcentral.com/submissions 